ror

TEMA LIVRE

\title{
Revendo a questão da saúde LGBT no âmbito da atenção primária à
}

saúde ${ }^{1}$

\author{
Daiane Regina Pinto ${ }^{2}$ \\ Roberth Steven Gutiérrez Murillo ${ }^{3}$ \\ Marcos de Jesus Oliveira ${ }^{4}$
}

Resumo: O texto constitui uma reflexão crítica sobre a Política Nacional de Saúde Integral de Lésbicas, Gays, Bissexuais, Travestis e Transexuais (PNSILGBT), com olhar especial para o contexto da Atenção Primária em Saúde (APS). Trata-se de um estudo qualitativo misto, de revisão documental e bibliográfica, que aborda a questão da assistência às premências sociossanitárias de usuários com múltiplas identidades de gênero e orientações sexuais no âmbito do Sistema Único de Saúde (SUS). O trabalho visou, concomitantemente, a destacar aspectos históricos que dizem respeito à criação, implementação e implantação da PNSILGBT nas redes de cuidado à saúde do SUS. 306 Considerando o objetivo traçado, foram incluídos artigos científicos com tal direção investigativa desenvolvidos no cenário da APS e elaborados em língua portuguesa. Na seleção dos materiais optou-se por utilizar os seguintes descritores: Saúde LGBT; PNSILGBT; Atenção Primária à Saúde; SUS. Por se tratar de uma das políticas nacionais de saúde específicas mais recentes no SUS, o presente trabalho evidenciou uma escassez de estudos voltados para a compreensão da atenção e assistência disponibilizada à comunidade LGBT no Brasil, informando que, se bem, a implementação da PNSILBGT é considerada uma das mais importantes conquistas em matéria de justiça social, futuros estudos ainda se fazem necessários, pois se reconhece a magnitude da temática para a reivindicação dos direitos fundamentais, haja vistas dos princípios doutrinários que regem a APS no SUS: universalidade, integralidade e equidade. Isso porque, apesar de existir, resistir e ocupar os espaços da sociedade brasileira, a efetivação da PNSILGBT ainda se encontra distante do objetivo almejado.

Palavras-chave: Saúde LGBT; Política Integral de Saúde LGBT; Sistema Único de Saúde; Equidade em Saúde.

\footnotetext{
${ }^{1}$ Trabalho de Conclusão de Residência apresentado ao Programa de Residência Multiprofissional em Saúde da Família - Universidade Federal da Integração Latino-Americana, como requisito obrigatório à obtenção do título de Especialista em Saúde da Família, pela primeira autora. A autora agradece ao Ministério da Educação, pelo auxílio financeiro concebido ao longo do programa (2018-2020).

${ }^{2}$ Psicóloga, Universidade Paranaense. Especialista em Saúde da Família, UNILA.

${ }^{3}$ Sanitarista, UNILA. Residente em Saúde da Família, UNILA. Mestrando em Gerontologia, Universidad Europea Del Atlántico, Espanha.

${ }^{4}$ Sociólogo, Universidade Regional do Noroeste do Estado do Rio Grande do Sul. Mestre em Literatura. Especialista em Gestão de Políticas Públicas em Gênero e Raça. Doutor em Sociologia, Universidade de Brasília.
}

Vol. 03, N. 13, Jan. - Abr., 2021 - http://periodicoscientificos.ufmt.br/ojs/index.php/rebeh/index 
Sendo a saúde um direito humano inalienável, o Sistema Único de Saúde (doravante SUS) deve garantir o máximo de justiça sociossanitária, sem prejuízo de qualquer natureza. Ao fazer equitativo o acesso às ações e aos serviços de saúde, o SUS se compromete de modo a alcançar dito propósito. Com isso, o sistema proporciona aos indivíduos o direito, "livre de preconceitos ou privilégios, ao acesso a todas as instituições de saúde em qualquer nível de atenção indispensável ao atendimento da necessidade sentida e tecnicamente identificada" (PONTES; CESSO; DE OLIVEIRA e GOMES, 2010, p. 576).

Estratégias e políticas mais específicas, para universalizar e melhorar o acesso aos serviços de saúde e, consequentemente, as condições de adoecimento, tratamento, reabilitação e cura, vêm sendo construídas desde antes da implantação do SUS (DE LIMA, 2017). Do anterior vale reter que o "acesso a serviços de saúde e equidade estão profundamente relacionados à capacidade de os sistemas de saúde se organizarem de modo a responder adequadamente às necessidades dos cidadãos" (BARROS et al., 2016, p. 265). Considerando a orientação sexual e a identidade de gênero como determinantes sociais da saúde e do processo de sofrimento e adoecimento decorrente do preconceito e do estigma social direcionado às pessoas Lésbicas, Gays, Bissexuais, Travestis e Transexuais (doravante LGBT) ${ }^{5}$, o Ministério da Saúde promulgou a Portaria $\mathrm{n}^{\mathrm{o}}$ 2.836, em 01 de dezembro de 2011, instituindo a Política Nacional de Atenção Integral à Saúde de Lésbicas, Gays, Bissexuais, Travestis e Transexuais (BRASIL, 2013).

As identidades de gênero e a orientação sexual divergem da norma heterossexual compulsória, desafiando à lógica binária e biológica/anatômica, cultural e religiosa, incorrendo muitas vezes a causa de uma série de violações de direitos

\footnotetext{
${ }^{5}$ Em épocas mais recentes, tem se tornado comum utilizar a expressão LGBTQIA+ para designar a diversidade de identidades, dissidências e expressões de gênero e de orientações sexuais. A opção pela expressão LGBT se deve ao fato desta ser a mais recorrente nos documentos sobre os quais o presente estudo se debruçou. Sua escolha não pretende, obviamente, apagar a pluralidade de vivências, trajetórias e experiências em torno das identidades sexuais e de gênero, já que estas estão amiúde interseccionadas por diferentes marcadores sociais de diferença tais como classe, raça, geração, localidade, entre outros.
} 
humanos fundamentais (NAGAMINE, 2019; POPADIUK et al., 2017). Em tempo, cabe recordar que, no âmbito da Saúde Coletiva, o universo simbólico em torno da diversidade sexual foi primordialmente construído pela ordem médica, a qual por muito tempo identificou e classificou o segmento LGBT como portadores, em particular, de patologia mental e desvio de condutas sexuais e de gênero (PEREIRA et al., 2017). Em função dessa acepção, enquanto componente moral, as pessoas que assumem identidades de gênero desviantes do padrão heteronormativo acabam passando por um processo de discriminação, justificado pela não adoção da normalidade já descrita e concretizada na forma de homotransfobia, qual seja definida como o medo ou ódio em relação a pessoas LGBT (DE LIMA, 2017; SARTI et al., 2019).

A discriminação, o desrespeito, o estigma social, as situações vexatórias e o preconceito são fatores que incidem fortemente na saúde desse segmento populacional, impactando diretamente no acesso ao serviço e programas de saúde, tendo em muitas ocasiões sua própria condição humana questionada ou negada, escancarando-se ainda mais nos casos de travestis, cujas violências são marcadas pela intensidade de estigmatização, discriminação, exclusão, agressão física e morte (DE LIMA, 2017). Por outro lado, a violência e suas variações, adjuntas aos diversos modos de preconceito, constituem sérias barreiras sociais na vida dessas pessoas, refletindo diretamente na qualidade de vida e de saúde, com especial menção à saúde mental. Nesse contexto, as instituições sanitárias devem ter um ambiente acolhedor, livre de preconceitos e de atenção integral à população LGBT, com reconhecimento de suas especificidades na oferta de ações e serviços correspondentes (POLIDORO et al., 2020).

No Brasil, a população LGBT está entre as minorias sociais marginalizadas com menor acesso aos serviços de saúde, e que não recebe a devida assistência em face aos julgamentos e juízos de valor de profisssionais dos serviços de saúde, cuja discriminação existe em diversos espaços da sociedade e também nos lugares de produção do cuidado (PEREIRA et al., 2017). Diante desse contexto de marginalização, este estudo qualitativo misto, de revisão documental e bibliográfica, aborda a questão da assistência às premências sociossanitárias de usuários com identidades múltiplas de gênero e orientações sexuais no âmbito do SUS. Visou, concomitantemente, a destacar 
aspectos históricos que dizem respeito à criação, implementação e implantação da PNSILGBT nas redes de cuidado do SUS.

Considerando o objetivo traçado, foram incluídos artigos científicos com tal direção investigativa desenvolvidos no cenário da Atenção Primária à Saúde (doravante APS) e elaborados em língua portuguesa. Na seleção dos materiais optou-se por utilizar os descritores: Saúde LGBT; PNSILGBT; Atenção Primária à Saúde; SUS. Na discussão dos dados, respeitou-se o posicionamento integral dos autores, elemento que permitiu, consequentemente, identificar similitudes e divergências na literatura científica.

Estruturalmente, o texto foi organizado em quatro partes. De começo, abraçase uma breve contextualização sobre o SUS e o direito constitucional à saúde. Em seguida, discutem-se alguns aspectos relacionados à construção de políticas públicas para as pessoas LGBT no cenário brasileiro. A terceira parte do trabalho oferece uma breve leitura descritiva sobre a Política Nacional de Saúde Integral de Lésbicas, Gays, Bissexuais Travestis e Transexuais (doravante PNSILGBT), destacando seus objetivos e sua abrangência no contexto do SUS. O trabalho encerra-se por meio de uma série de apontamentos multidimensionais, que toma como norte a saúde LGBT e os principais desafios enfrentados na APS.

\section{Sistema Único de Saúde: considerações iniciais}

O SUS foi instituído pela Constituição Federal de 1988 e consolidado pelas leis $\mathrm{n}^{\mathrm{o}}$. 8.080 e $\mathrm{n}^{\mathrm{o}}$. 8.142, de 1990. Surgiu como resultado de anos de luta de um movimento denominado de Reforma Sanitária, tendo como uma de suas principais características a garantia constitucional de que a saúde é um direito de todo cidadão e dever do Estado, a ser realizado mediante o acesso dos indivíduos de modo igualitário (CARVALHO, 2013). É válido destacar que a expressão "Reforma Sanitária" foi usada para fazer referência ao conjunto de ideias que apontavam as mudanças e transformações necessárias na área da saúde no Brasil, em busca da melhoria das condições de vida da população (PAIVA e TEIXEIRA, 2014). 
Assim, a garantia da saúde como um direito constitucional do cidadão e dever do Estado se encontra sustentada pelo artigo 196 da nova Constituição Federal, subscrevendo que o Estado deve "garantir mediante políticas sociais e econômicas que visem à redução do risco de doença e de outros agravos e ao acesso universal e igualitário às ações e serviços para a promoção, proteção e recuperação" (BRASIL, 1988).

De acordo com Santos (2010), o direito à saúde, nos termos do artigo 196, pressupõe que o Estado deve não apenas garantir serviços públicos de promoção, proteção e recuperação da saúde, mas também adotar políticas econômicas e sociais que melhorem as condições de vida da população, buscando evitar ou diminuir o risco de adoecimento das pessoas. Nessa mesma linha de pensamento, Aith (2001) realiza importantes apontamentos, indicando que:

A Constituição Federal, ao mesmo tempo em que reconhece a Saúde como direito de todos, confere ao Estado a responsabilidade de organizar um conjunto de ações e serviços públicos de saúde capazes de reduzir o risco de doenças e de outros agravos a saúde, bem como de garantir à população o acesso universal e igualitário às ações e serviços para promoção, proteção e recuperação da saúde (AITH, 2001, p. 201).

No intuito de cumprir esse importante objetivo, a Constituição Federal criou o SUS, como norma constitucional que reúne os instrumentos jurídicos, administrativos, institucionais e financeiros para desenvolver as atividades necessárias para a garantia jurídica desse direito. Assim, o SUS representa a mais importante garantia jurídica do direito à saúde, na medida em que integra e organiza diversas outras garantias concretas (AITH, 2001). Igualmente, serve notar que o direito à saúde "tem sua garantia claramente vinculada às políticas sociais e econômicas, as diretrizes do sistema expressamente formuladas, envolvendo a participação da comunidade" (DALLARI, 2009, p. 9).

Com a promulgação da Lei Orgânica da Saúde nº. 8080, de 1990, posteriormente complementada pela lei $\mathrm{n}^{\circ}$. 8142, de 1990, fortaleceu-se o direito à saúde como direito universal e foi reforçado o conceito ampliado de saúde, anteriormente enunciado na Constituição Federal de 1988, replicando-o nos seguintes 
termos: "a saúde é um direito fundamental do ser humano, devendo o Estado prover as condições indispensáveis ao seu pleno exercício" (BRASIL, 1990).

Autores como Noronha, Lima e Machado (2012) defendem que a discriminação no acesso aos serviços de saúde é inaceitável, pois os serviços de saúde não devem ser direcionados a grupos sociais específicos visando de forma arbitrária ou discriminatória. Para eles, o princípio da igualdade significa, a um só tempo, tratamento isonômico e equitativo dos usuários do sistema de saúde, garantindo-se a todos o acesso aos serviços de que necessitem na medida de suas necessidades (NORONHA et al., 2012).

Outrossim, o reconhecimento do direito à saúde como direito social para todos provocou uma reorganização não só no âmbito sanitário, refletindo sobre todas as dimensões da vida humana. Trata-se de uma série de responsabilizações admitidas pelo Estado em prol do bem-estar e desenvolvimento multidimensional de seus cidadãos.

\section{Construção de políticas públicas para a população LGBT}

Em sua tese de doutorado, Moscheta (2011) apud De Lima (2017) identificou três momentos na história das intervenções sobre a população LGBT no âmbito sanitário. O primeiro momento se inicia com as primeiras classificações patologizantes de sexualidades e gêneros desviantes, cujas intervenções eram corretivas e propunham a cura. Em seguida, teve-se a desconstrução de patologias instuídas anteriormente e pela emergência da AIDS, momento caracterizado por uma lógica epidemiológica cujo foco objetivava corrigir, controlar e/ou modificar o estilo de vida de um determinado grupo social. No último momento, observou-se o fortalecimento do movimento social e sua articulação com políticas públicas e a decorrente formulação de propostas para a garantia dos direitos humanos que incluiriam uma transformação social no combate à discriminação e ao preconceito (DE LIMA, 2017).

A construção de políticas para a população LGBT foi e continua a ser um caminho longo no Brasil, contudo, desde as décadas de 70 e 80, lésbicas, gays, bissexuais, travestis e transexuais têm se fortalecido na busca da garantia de seus direitos, frente à discriminação e à marginalização a que são sujeitos (BEZERRA et al., 
2019). Tratava-se de grupos articulados, "que costumavam reunir-se em lugares sociais, como bares e clubs, ainda em pleno momento de ditadura" (QUERINO et al., 2017, p. 47). Porém, no entendimento de Duarte (2014), houve maior protagonismo político LGBT a partir no início do novo milênio, através de uma maior abertura para discussões sobre a diversidade sexual.

Em 2004, como consequência dos direitos dessa população serem expressos em documentos e normativas públicas ao lado de outras lutas igualmente importantes, o Ministério da Saúde e o Conselho Nacional de Combate à Discriminação lançaram o programa 'Brasil Sem Homofobia', organizado pelo Governo Federal em parceria com a sociedade civil, cujo objetivo central foi a organização dos gestores e trabalhadores, visando à modificação de comportamento destes, tendo o acolhimento, a não discriminação e a luta contra a qualquer forma de preconceito uma de suas bandeiras (BRASIL, 2013). Para Bezerra et al. (2019, p. 315), fica claro que o referido programa se originou "em resposta aos debates e à ausculta de demandas de representações do movimento social LGBT".

Em 2007, o Ministério da Saúde lançou o Plano Nacional de Enfrentamento da Epidemia de AIDS e DST entre Gays, outros Homens que fazem Sexo com Homens (HSH) e Travestis (BRASIL, 2007). Apesar de algumas instâncias apontarem para a não transcendência e magnitude da referida doença, alertando que a existência de um programa de AIDS poderia estar desviando a atenção de outras questões mais importantes, como a desnutrição e até mesmo de outras doenças infecciosas, o plano foi um marcador legal significativo para "a melhoria do acolhimento e da resposta à epidemia de AIDS entre esses grupos, no contexto do Sistema Único de Saúde, e dos demais setores responsáveis pela execução do Programa Brasil Sem Homofobia" (BRASIL, 2007). No campo da saúde, sua construção partiu da perspectiva de que a "resposta nacional à epidemia não é uniforme no país, que existem diferentes contextos de vulnerabilidade e que a vivência da sexualidade impõe novos desafios para a abordagem de promoção da saúde" (DE LIMA, 2017).

A $8^{\text {a }}$ Conferência de Gays, Lésbicas, Bissexuais, Travestis e Transexuais (doravante $8 \mathrm{CGLBT}$ ), foi um importante divisor de águas na gestão de políticas públicas. Ocorrida em Brasília entre os dias 5 e 8 de julho de 2008, oportunizou como 
um dos principais avanços a elaboração do Plano Nacional de Promoção da Cidadania e Direitos Humanos de Lésbicas, Gays, Bissexuais, Travestis e Transexuais, o qual traz as diretrizes e ações para a elaboração de Políticas Públicas voltadas para esse segmento. O principal objetivo deste Plano é a "construção de políticas públicas de inclusão social e de combate às desigualdades para a população LGBT, primando pela intersetorialidade e transversalidade na proposição e implementação dessas políticas” (BRASIL, 2013, p. 9).

Conseguintemente, em 2011, foi publicado o primeiro documento que definiu, orientou e regulamentou a atenção à saúde exclusivamente para a população LGBT, que fora fruto da 8CGLBT (BRASIL, 2013a), pela Portaria $n^{\circ} .2 .836$, de 01 de dezembro de 2011. Anos mais tarde, em 2013, o Ministério da Saúde, admitindo a "necessidade de identificar, estruturar, ampliar e aprimorar a rede de atenção à saúde e a linha de cuidado de transexuais e travestis", acabou por redefinir e ampliar sua abrangência, pela Portaria $\mathrm{n}^{\mathrm{o}}$ 2.803, de 19 de Novembro de 2013, a qual decretou o processo transexualizador no SUS (BRASIL, 2013).

Assim, o processo de evolução das políticas públicas voltadas para a população LGBT foi avançando conforme foi sendo conquistada visibilidade às condições de sujeição às diversas formas de preconceitos, discriminações e violências, cujo contorno foi dado pelas condições de saúde que se suspeitavam haver nessas pessoas. O discurso societário mudou conforme se avançou na história, ora partindo do indivíduo doente, passando pelo grupo de risco e chegando à sociedade desigual. Saímos da predominância das práticas corretivas, passamos pelas ações preventivas e chegamos ao combate à discriminação, embora todas estas práticas ainda possam ser identificadas e coexistam atualmente (MOSCHETA, 2011 apud DE LIMA, 2017).

\section{Política Nacional de Saúde Integral de Lésbica, Gays, Bissexuais, Travestis e Transexuais (PNSILGBT)}

A PNSILGBT é um divisor de águas para as políticas públicas de saúde no Brasil e um marco histórico de reconhecimento das demandas desta população em condição de vulnerabilidade. É também um documento norteador e legitimador das suas 
necessidades e especificidades, em conformidade aos postulados de equidade previstos na Constituição Federal e na carta dos usuários do SUS (BRASIL, 2013). É uma iniciativa dentro dos princípios do SUS, para a construção de mais equidade. O compromisso do Ministério da Saúde com a redução das desigualdades constitui uma das bases do Programa Mais Saúde - Direito de Todos - (BRASIL, 2008), lançado em 2008, visando à reorientação das políticas de saúde com o objetivo de ampliar o acesso a ações e serviços de qualidade (BRASIL, 2013).

A dita política tem como particularidade ideológica o reconhecimento dos efeitos da discriminação e da exclusão no ciclo saúde-doença-cuidados da população LGBT. Suas diretrizes e seus objetivos se encontram, portanto, voltados para mudanças na determinação social da saúde, com vistas à redução das desigualdades relacionadas a esse segmento populacional. De forma análoga, contempla as fases de promoção, prevenção, recuperação e reabilitação da saúde, além do incentivo à produção de conhecimentos e o fortalecimento da representação do segmento nas instâncias de participação popular. O respeito sem preconceito e sem discriminação é preconizado como fundamento para a humanização nessas fases. Para que tal efetivação ocorra, a PNSILGBT articula um conjunto de ações e programas que constituem medidas concretas a serem implementadas, em todas as esferas de gestão do SUS, particularmente nas secretarias estaduais e municipais de saúde. Este processo de implementação deve ser acompanhado, cotidianamente, pelos respectivos conselhos de saúde e apoiado, de forma permanente, pela sociedade civil (BRASIL, 2013).

Compreender a determinação social no ciclo saúde-doença-cuidados das coletividades é admitir que a exclusão social decorrente do desemprego, da falta de acesso à moradia e à alimentação digna, bem como da dificuldade de acesso à educação, saúde, lazer e cultura interferem, diretamente, no desenvolvimento pleno (OLIVEIRA e SOARES, 2020). Requer, ademais, a compreensão de que todas as formas de discriminação como, por exemplo, homotransfobias que compreendem lesbofobia, gayfobia, bifobia, travestifobia e transfobia devem ser consideradas na determinação social de sofrimento e de doença (BRASIL, 2013). Ao mesmo tempo, cumpre relembrar que tais formas de preconceito não ocorrem de maneira isolada das outras formas de discriminação social, tudo pelo contrário, elas caminham ao lado e se reforçam pelos 
preconceitos do machismo, o racismo e a misoginia (ALBUQUERQUE, 2013;

OLIVEIRA et al., 2020).

Inúmeros entraves assistenciais têm sido identificados na literatura multidisciplinar preocupada por analisar as implicações do momento pré e pósaprovação da PNSILGBT. Dentre os direitos conquistados por esse público, está o respeito à personalidade, isto é, o uso do nome social por travestis e transexuais, pelo qual preferem ser chamados(as), em contraposição ao nome do registro civil, que não corresponde ao gênero com o qual se identificam. Nos serviços de saúde, esse direito se encontra garantido pela Portaria $\mathrm{n}^{\mathrm{o}} 1.820$, de 2009, que descreve que o usuário deve ser identificado:

Pelo nome e sobrenome civil, devendo existir em todo documento do usuário e usuária um campo para se registrar o nome social, independente do registro civil sendo assegurado o uso do nome de preferência, não podendo ser identificado por número, nome ou código da doença ou outras formas desrespeitosas ou preconceituosa (BRASIL, 2009).

A falta de respeito ao nome escolhido pelas pessoas travestis e transexuais se configura como uma violência que acontece diariamente nas suas vidas sociais (BEZERRA et al., 2019). Em decorrência disso, e considerando a discriminação que atinge tais cidadãos e cidadãs quando buscam serviços universais de atendimento à saúde, viabilizar o uso do nome social tanto oral quanto nos documentos e prontuários, além de ser uma obrigação legal, é também viabilizar caminhos para a concretização da atenção integral em saúde (BRASIL, 2013).

A validação da escolha realizada pelo(a) usuário(a) se torna um aspecto essencial na assistência a eles(as) oferecida nos diversos dispositivos sanitários e sociais. É, desse modo, um elemento que possui o potencial de fortalecer ou enfraquecer o vínculo entre o profissional sanitário e o(a) usuário(a), justamente porque "o nome representa a expressão máxima do ser humano, da qualificação de coisas, propostas e objetos” (MONTESCHIO-JUNIOR, 2018, p. 6). Por parecido, torna-se válido retomar o posicionamento crítico de Popadiuk, Oliveira e Signorelli (2017, p. 1510), sobretudo, quando afirmam que "não se trata apenas do estabelecimento de diretrizes para a atenção integral no sentido estrito, mas de um conjunto de ações necessárias à garantia 
do direito à saúde circunscrita à passagem para a vivência social no gênero em desacordo com o sexo de nascimento".

À vista da complexa situação sociossanitária do grupo LGBT e, especialmente, das evidências que a orientação sexual e a identidade de gênero têm na determinação social e cultural da saúde, o Ministério da Saúde instituiu a PNSILGBT, abraçando o desafio de brindar uma atenção sociossanitária integral e humanizada a todos os cidadãos, ora incluindo aqueles não heterossexuais ou cisgêneros. Sem embargo, pelo fato de ser uma política recente, ainda registram-se práticas preconceituosas que impossibilitam o real gozo dos direitos de uma parcela de usuários e usuárias considerável que, além das dificuldades correntes, sofrem ainda constrangimentos diversos e outros tipos de contratempos no próprio sistema de saúde (PREUSS e MARTINS, 2018).

\section{Saúde da população LGBT na APS e seus principais desafios assistenciais}

No Brasil, a APS está implantada como uma política de Estado, sendo a porta de entrada principal e prioritária aos serviços de saúde, na coordenação do cuidado e referência na Rede de Atenção à Saúde. As equipes de APS são consideradas referências pelo cuidado de certa população em um território definido sob sua responsabilidade sanitária (PONTES et al., 2009). Dessa forma, devem estar acessíveis para acolher a demanda espontânea e realizar o acompanhamento dessa população de maneira longitudinal por meio de ações nas esferas assistenciais e coordenar seu cuidado integral na Rede de Atenção à Saúde. Por tanto, é fundamental que ela se oriente pelos princípios da universalidade, da acessibilidade, do vínculo, da continuidade do cuidado, da integralidade da atenção, da responsabilização, da humanização, da equidade e da participação social (BRASIL, 2012).

Ressalta-se que, como política de Estado e sustentadora do SUS, o atendimento na APS deve respeitar seus princípios fundamentais, considerando a singularidade, a inserção cultural, os determinantes e condicionantes sociais da saúde da população, cujas ações devem convergir para a proteção, prevenção, recuperação e promoção da 
saúde. Nesse sentido, esforços devem ser feitos para minimizar as desigualdades e a exclusão de grupos sociais, atendendo a diversidade humana, fator que remete à população LGBT (BRASIL, 2013; RIOS, 2020; SANTOS, 2019). Diferente das pessoas cis-heterossexuais, as pessoas que integram a população LGBT precisam se assumir publicamente em vários momentos da vida, afirmando-se em suas orientações sexuais e identidades de gênero tanto para si quanto para sua família, amigos, colegas de trabalho, em todos os contextos que estiverem inseridos. Dito processo, de aceitação pessoal, familiar e social pode desencadear vários problemas relacionados à saúde mental (SANTOS, 2019; BRASIL 2013).

Outrossim, não é segredo que a população bissexual é frequentemente invisibilizada, inclusive por profissionais sanitários. Os empecilhos simbólicos de acesso da população LGBT aos serviços sociossanitários têm sido frequentemente esgrimidos, não apenas em relação aos homossexuais masculinos, mas também para todos os grupos que compõem a diversidade de orientação sexual e de identidade de gênero (BEZERRA et al., 2019; DE LIMA, 2017; SANTOS, 2019).

Concernente às mulheres lésbicas e bissexuais cisgêneras, por exemplo, a discriminação associada ao despreparo dos profissionais de saúde é a principal barreira para que elas assumam sua orientação sexual durante o atendimento. No que se refere às travestis e transexuais, as barreiras simbólicas ao acesso e o comprometimento da qualidade de atenção têm sido relatadas com maior veemência, influenciando desde a dificuldade em se cumprir a determinação de uso do nome social nos prontuários quanto o ainda persistente processo de psiquiatrização da condição de transexualidade, para a garantia da cirurgia de redesignação sexual (PEREIRA et al., 2017; PAULINO; RASERA e TEIXEIRA, 2019).

Na pesquisa realizada por Pereira et al. (2017) no município de Teresina-PI, com médicos de sete unidades de saúdes a respeito de como são organizadas as ações e serviços dirigidos à população LGBT, os resultados apontaram que existe uma unanimidade no discurso, em que alega não haver "nada específico para eles" (segundo a fala de um dos médicos entrevistados). Entretanto, observa-se que a justificativa é baseada no conceito arraigado de igualdade, focado na universalização de direitos. $\mathrm{O}$ ponto de vista da classe médica nem sempre consegue velar-se, de modo que o discurso,

Vol. 03, N. 13, Jan. - Abr., 2021 - http://periodicoscientificos.ufmt.br/ojs/index.php/rebeh/index 
embora cuidadoso, evidencia a inobservância médica à PNSILGBT (PEREIRA et al., 2017).

É indiscutível a influência negativa que os padrões de caráter heteronormativos enraizados na sociedade brasileira têm dentro das dimensões da saúde. É certo, ainda, que essa influência transcende fortemente em condutas adotadas pelos próprios profissionais da saúde, criando barreiras de acesso e impedindo o gozo dos direitos fundamentais outorgados a todo indivíduo. Ao mesmo tempo, dito cenário adjunta uma série de comportamentos indesejados, que vão de encontro com os princípios doutrinários do SUS, quais sejam: universalidade, integralidade e equidade em saúde. A situação presta fundamento para os baixos níveis de demanda aos serviços e programas de saúde por parte da comunidade LGBT (PEREIRA et al., 2017). Acrescentando ao ponto anterior, Silva et al. (2020, p. 11) detêm que a:

Discriminação, óbices de diálogo entre profissionais da saúde e LGBT, além da violação quanto ao uso do nome social, manifestam-se como entraves ao acesso de pessoas LGBT aos serviços de saúde, contribuindo para o adoecimento, na medida em que os nega e dificulta cuidados em saúde. É essencial a inclusão desta temática nos currículos da saúde, para que todos os profissionais da saúde tenham o conhecimento dos fundamentos necessários para proporcionar acolhimento, prevenção, promoção e terapêutica de qualidade à população LGBT.

As necessidades específicas e os desafios multidimensionais enfrentados pela população LGBT exigem qualificação/aprimoramento profissional, motivo pelo qual a supressão do treinamento no serviço poderia perpetuar o preconceito e a discriminação, resultando em cuidados de baixa qualidade e no aumento da incidência de doenças e seus fatores de risco (SANTOS; SILVA e PEREIRA, 2019). Sendo assim, deve-se investir na educação permanente e continuada, através de diretrizes práticas para que haja uma oferta ampla, abrangente, científica e humana a esse grupo populacional (SANTOS et al., 2019). Com isso, não se trata simplesmente de promover o conhecimento teórico (o qual se julga ser essencial), mas sim materializá-lo, de forma em que todas as categorias profissionais da saúde consigam distinguir a potencialidade da prática sanitária ora desamarrada de julgamentos prévios, quaisquer que esses sejam. 
O Dossiê "Saúde das Mulheres Lésbicas - Promoção da Equidade e da Integralidade", publicado pela Rede Feminista de Saúde em 2006, concilia dados pertinentes que evidenciam as desigualdades de acesso aos serviços de saúde por mulheres lésbicas e bissexuais. Informa, por exemplo, que cerca de $40 \%$ das mulheres que procuraram algum tipo de atendimento sanitário não revelam sua orientação sexual. Dentre as usuárias que a revelam, 28\% referiram maior rapidez do atendimento do médico e $17 \%$ afirmam que estes deixaram de solicitar exames considerados por elas como necessários. Com relação ao exame preventivo de câncer cérvico uterino (Papanicolau), o Dossiê cita dados da pesquisa realizada em 2002, pela Coordenação DST2/AIDS do Ministério da Saúde, que demonstram que, entre as mulheres cisgêneras heterossexuais, a cobertura na realização desse exame nos últimos três anos é de 89,7\%. No tangente às mulheres lésbicas e bissexuais, a cobertura caiu para $66,7 \%$, mesmo com maior grau de escolaridade e renda (BRASIL, 2013).

Embora a epidemia da AIDS tenha provocado que o SUS focasse suas prioridades também nas pessoas travestis e transexuais, conferindo-lhes visibilidade negativa, uma vez que atualmente é conhecido que os problemas de saúde destas pessoas são bem mais complexos e suas demandas são numerosas (PRADO e SOUZA, 2017). A prostituição compulsória para as travestis significa não apenas sua sobrevivência financeira, mas também a possibilidade de pertencimento social, que lhes é negado em outros espaços, como foi explicitada por Tussi (2006). Para o autor, é na rua que as travestis exercitam o feminino, a afetividade, as relações sociais, mas é também o espaço de consumo em geral, inclusive de drogas, silicone industrial, hormônios e outros medicamentos (TUSSI, 2006).

Em complemento, a rua e a prostituição poderiam acarretar maiores riscos de contrair infecções sexualmente transmissíveis e vivenciar diversos tipos de violência, o que torna esse grupo ainda mais vulnerável. A depressão, as crises de ansiedade e sensações de pânico parecem ser frequentes entre as travestis e transexuais. Trata-se de um grupo de indivíduos altamente acometidos por agravos mentais, circunstância que dimensiona ainda mais a complexidade assistencial que os(as) cerca (OLIVEIRA, 2014; PAULINO et al., 2019). 
Ao respeito, inúmeros relatórios, a nível nacional e internacional, têm-se preocupado por demonstrar o impacto negativo que os comportamentos preconceituosos trazem à integralidade dessas pessoas. Em estudos realizados pela Associação Nacional de Travestis e Transexuais - ANTRA, no ano de 2018, estimou-se que $42 \%$ da população Transexual já passou por tentativa de suicídio. O relatório "Transexualidades e Saúde Pública no Brasil”, do Núcleo de Direitos Humanos e Cidadania LGBT e do Departamento de Antropologia e Arqueologia da Universidade Federal de Minas Gerais, revelou que $85,7 \%$ dos homens trans já consideraram o suicídio ou tentaram concretizar o ato suicida (MARTINS, 2018). Desse modo, faz-se jus afirmar que o cenário epidemiológico discutido demanda intervenções mais eficazes e eficientes, que expressem resultados imediatos e a longo prazo.

No que compete às diretrizes clínicas para a prestação de serviços de atenção primária e planejamento familiar para a população LGBT, Santos (2019) aponta que há evoluções importantes que merecem ser mencionadas. O referido autor acena para o debate acerca da importância de identificar os determinantes sociais da saúde em usuários LGBT, que refletem diretamente em sua qualidade de vida. Com isto, há que se refletir e colocar nas pautas de debates sociossanitários, tanto na formação quanto nas atividades de educação permanente nos serviços de saúde, e também nos eventos científicos da área, de modo a considerar a especificidade do contexto de saúde e de vida das pessoas LGBT, ampliando o diálogo e compartilhando os saberes necessários às práticas de cuidado a serem incorporadas no cotidiano da APS.

Estudiosos como Gomes et al. (2018) destacam as potencialidades da escuta ativa nos diversos campos de contato entre a população LGBT e o SUS, uma vez que esta viria a influenciar positivamente a promoção de ações integrais, aproximando ditos(as) usuários(as) ao sistema de saúde. Ciente de que as premências sociossanitárias respondem pelas subjetividades próprias de cada sujeito (usuários/as), os/as profissionais sanitários(as) devem partir de uma objetivação assistencial desfeita de prejuízos e/ou estigmatizações sociais, fato que demanda, por sua vez, de libertar-se de suas próprias acepções. Sobre essa mesma linha apreensiva, Paulino et al. (2019, p. 3) defendem que "a qualificação consistente em atenção à saúde da população LGBT é rara, o que leva a crer que esforços futuros serão necessários para desenvolver, nos 
currículos médicos, esse tema". Por último, os autores reconhecem que "antes de qualquer coisa, o seu reconhecimento como humano, sujeito de direitos, com demandas específicas e necessidade de serviços de saúde que só ele pode dizer, mas que só dirá, se for acolhido no serviço de saúde" (idem, ibidem, p. 12).

\section{Considerações Finais}

Analisar a assistência providenciada aos usuários LGBT, no âmbito da APS, constitui uma prática que deve ser institucionalizada em todos os serviços e programas locais de saúde, na medida em que permite qualificar o impacto que a PNSILGBT tem produzido no arranjo dos direitos humanos e sociais admitidos no território brasileiro. Mais precisamente, discutir e problematizar os mecanismos/intervenções direcionados a atender às demandas da população LGBT, constitui uma importante ferramenta para a promoção da democracia sanitária e a justiça social.

Em consonância com o anterior, o presente trabalho permitiu observar que, apesar de várias conquistas auferidas pelos grupos vulneráveis (minorias sociais), ainda existem desafios gritantes dentro dos serviços de saúde, não simplesmente negam o direito a uma atenção à saúde digna e integral para esse grupo populacional, mas também acabam por retraçar o desenvolvimento pleno do SUS, pois impedem o real gozo dos princípios da universalidade, integralidade e equidade em saúde. Espera-se, dos profissionais da saúde, a promoção de comportamentos éticos e humanizados, que primem pelo bom senso, sobrepondo suas atribuições profissionais sobre seus julgamentos morais.

Por outro lado, admite-se que o presente trabalho apresentou algumas limitações. Primeiramente, o desenho metodológico do trabalho, do tipo revisão documental e bibliográfica, limitou a quantidade de trabalhos discutidos, considerando unicamente àqueles que responderam ao objetivo traçado. Em segundo lugar, o ambiente no qual os trabalhos deveriam ter sido desenvolvidos, haja vistas dos diversos dispositivos da APS, impossibilitou realizar comparações dicotômicas com os outros níveis da atenção à saúde. Como recomendação, instila-se a realização de estudos futuros, que se importem por analisar, através de diferentes perspectivas metodológicas, 
as significações que a PNSILGBT traz tanto para os profissionais da saúde (no nível assistencial e gerencial), quanto para os próprios usuários por ela abrigados.

Finalmente, ainda que não tenha sido o objetivo do presente artigo discutir os efeitos da pandemia da COVID-19 ocasionada pelo coronavírus SARS-CoV-2 na saúde mental da população LGBT, sua escrita foi feita durante este período e, por isso, não pode passar totalmente incólume à questão. Estudos recentes destacam que as vulnerabilidades sociais decorrentes do estigma e da discriminação por identidade de gênero ou por orientação sexual podem tornar o vírus ainda mais letal. Inúmeras investigações confirmam que pessoas LGBT estão mais propensas ao desenvolvimento de quadros de depressão e de ansiedade assim como à ideação suicida quando comparadas à população heterossexual (BORDIANO et al, 2021). Os achados coincidem, portanto, com o argumento da presente pesquisa e dá ainda mais força à necessidade de um olhar atento às vulnerabilidades sociais produzidas por condições de gênero e de orientação sexual no campo da saúde para que os princípios de universalidade, integralidade e equidade do SUS sejam, de fato, efetivados.

\section{Referências bibliográficas}

AITH, Fernando. "O Sistema Único de Saúde (SUS) como garantia fundamental do direito à saúde no Brasil”. In: SANTOS, Lenir. Direito da saúdo no Brasil. Campinas, SP: Ed. Saberes. Edição: 1ª, 2001. 201p.

ALBUQUERQUE, Grayce Alencar; GARCIA, Cíntia de Lima; ALVES, Maria Juscinaide Henrique; QUEIROZ, Cícera Monalisa Holanda Teles; ADAMI, Fernando. Homossexualidade e o direito à saúde: um desafio para as políticas públicas de saúde no Brasil. Saúde em Debate. 37(98):516-524, 2013.

BARROS, Fernando Passos Cupertino; LOPES, Jéssica de Souza; MENDOÇA, Ana Valéria Machado; DE SOUZA, Maria Fátima. Acesso e equidade nos serviços de saúde: uma revisão estruturada. Saúde em Debate, 40(110):264-271, 2016.

BEZERRA, Marcos Vinicius da Rocha; MORENO, Camila Amaral; PRADO, Nília Maria de Brito Lima; DOS SANTOS, Adriano Maia. Política de saúde LGBT e sua invisibilidade nas publicações em saúde coletiva. Saúde em Debate. 43(8):305-323, 2019. 
BORDIANO, Geovani; LIBERAL, Suzana Pacheco; LOVISI, Giovanni Marcos; ABELHA, Lucia. COVID-19, vulnerabilidade social e saúde mental das populações LGBTQUIA+. Cad. Saúde Pública, 37(3), 2021.

BRASIL. Constituição (1988). Constituição da República Federativa do Brasil. Brasília, DF: Senado Federal: Centro Gráfico, 1988. 292 p.

BRASIL. Ministério da Saúde. Lei. No 8.080, de 19 de setembro de 1990. Dispõe sobre as condições para a promoção, proteção e recuperação da saúde, a organização e o funcionamento dos serviços correspondentes e dá outras providências. Brasília, 1990.

BRASIL. Ministério da Saúde. Plano Nacional de Enfrentamento da Epidemia de AIDS e das DST entre Gays, HSH e Travestis. Brasília, 2007.

BRASIL. Ministério da Saúde. Mais saúde direito de todos. Diretoria Executiva. Brasília, 2008.

BRASIL. Ministério da Saúde. Gabinete do Ministro. Portaria $\mathbf{n}^{\mathbf{0}} \mathbf{1 . 8 2 0}$, de 13 de agosto de 2009. Dispõe sobre os direitos e deveres dos usuários da saúde. Brasília, 2009 .

BRASIL. Ministério da Saúde. Secretaria de Atenção à Saúde. Departamento de Atenção Básica. Política Nacional de Atenção Básica. Brasília: Ministério da Saúde, 2012 .

BRASIL. Ministério da Saúde. Secretaria de Gestão Estratégica e Participativa. Departamento de Apoio à Gestão Participativa. Política Nacional de Saúde Integral de Lésbicas, Gays, Bissexuais, Travestis e Transexuais. Brasília, 2013.

BRASIL. Portaria $n^{\circ} 2.436$, de 21 de setembro de 2017. Aprova a Política Nacional de Atenção Básica, estabelecendo a revisão de diretrizes para a organização da Atenção Básica, no âmbito do Sistema Único de Saúde (SUS), 2017.

CARVALHO, Vanessa Azambuja de. As representações sociais de mulheres lésbicas sobre atenção à sua saúde. Trabalho de Conclusão de Curso de Especialização. Universidade Federal do Rio Grande do Sul. 50p, 2013.

DALLARI, Sueli Gandolfi. A construção do direito à saúde no Brasil. Revista Brasileira de Direito Sanitário, 9(3):9-34, 2009.

DE LIMA, Cristiano Viana. Sentidos de profissionais da psicologia sobre acesso da população LGBT na Atenção Básica em saúde de Maringá, PR: quatro mitos perniciosos. Tese (Mestrado em Psicologia). Centro de Ciências Humanas, Letras e Artes. Universidade Estadual de Maringá, 2017. 
DUARTE, Cristina Maria Rabelais. Equidade na legislação: um princípio do sistema de saúde brasileiro? Ciência \& Saúde Coletiva. 5(2):443-463, 2000.

GOMES, Sávio Marcelino; DE SOUZA, Luciana Maria Pereira; VASCOCELOS, Thaissa Machado; NAGASHIMA, Alynne Mendoça Saraiva. O SUS fora do armário: concepções de gestores municipais de saúde sobre a população LGT. Saúde e Sociedade. 27(4):1120-33, 2018.

MARTINS, Helena. "Número de assassinatos de travestis e transexuais é o maior em anos no Brasil”. Agência Brasil, 2018.

MONTESCHIO-JUNIOR, Anisio. O nome e sua importância histórica: uma análise sobre o Direito da Personalidade. Dissertação de Mestrado em Ciências Jurídicas do Centro Universitário de Maringá - UNICESUMAR- Maringá - PR, 2018.

NAGAMINE, Renata Reverendo Vidal Kawano. Os direitos de pessoas LGBT na ONU (2000-2016). Sexualidad, Salud y Sociedad. 31(1):28-56, 2019.

NORONHA, José C. LIMA, Luciana D. MACHADO, Cristiani V. "O Sistema Único de Saúde - SUS". In: GIOVANELLA, Ligia (org) Políticas e Sistema de Saúde no Brasil. 2. Ed. Rev. e amp. / organizado por Lígia Giovanella, Sarah Escorel, Lenaura de Vasconcelos Costa Lobato et al., - Rio de Janeiro: Editora Fiocruz, 2012.

OLIVEIRA, Esmael Alves; OLIVEIRA, Janaira; DO NASCIMENTO, Letícia Carolina Pereira; LOPES, Moisés. Reflexões em torno da saúde da população LGBT: cruzando problemas, temas e perspectivas. Revista Brasileira de Estudos da Homocultura. 3(11):46-61, 2020.

OLIVEIRA, Marcos de Jesus. Uma etnografia sobre o atendimento psicoterapêutico a transexuais. Estudos Feministas. 22(3):839-62, 2014.

OLIVEIRA, Tibério Lima; SOARES, Suamy Rafaely. Uma análise marxista sobre os direitos humanos LGBTI+ no Brasil contemporâneo. Revista Brasileira de Estudos da Homocultura. 3(10):223-251, 2020.

PAIVA, Carlos Henrique Assunção; TEIXEIRA, Luiz Antonio. Reforma sanitária e a criação do Sistema Único de Saúde: notas sobre contextos e autores. História, Ciências, Saúde - Manguinhos. 21(1):15-35, 2014.

PAULINO, Daniel Borges; RASERA, Emerson Fernando; TEIXEIRA, Flavio do Bonsucesso. Discursos sobre o cuidado em saúde de Lésbicas, Gays, Bissexuais, Travestis, Transexuais (LGBT) entre médicas(os) da Estratégia Saúde da Família. Interface (Botucatu). 23:e180279, 2019.

PEREIRA, Edson Oliveira; FERREIRA, Breno de Oliviera; DO AMARAL, Gabriella Sorgatto; CARDOSO, Camila Vital et al. Unidades Básicas de Saúde em Teresina-PI e 
o acesso da população LGBT: o que pensam os médicos? Tempus Actas de Saúde Coletiva. 11(1):51-67, 2017.

POLIDORO, Maurício; CANAVESE, Daniel; BALDIGEN, Aline Armiliato; GARCIA, Taise Cristina; SILVA, Mariana Martins et al. Mulheres lésbicas e violência: análise das notificações de violência no estado do Rio Grande do Sul. Revista Brasileira de Estudos da Homocultura. 3(11):7-18, 2020.

PONTES, Ana Paula Munhen; CESSO, Rachel Garcia Dantas; DE OLIVEIRA, Denize Cristina; GOMES, Antonio Marcos Tosoli. O princípio de universalidade de acesso aos serviços de saúde: o que pensam os usuários? Escola Anna Nery. 13(3):500-07, 2009.

PONTES, Ana Paula Munhen; CESSO, Rachel Garcia Dantas; DE OLIVEIRA, Denize Cristina; GOMES, Antonio Marcos Tosoli. Facilidades de acesso reveladas pelos usuários do sistema único de saúde. Revista Brasileira de Enfermagem REBEn. 63(4):574-80, 2010.

POPADIUK, Gianna Schreiber; OLIVEIRA, Daniel Canavese; SIGNORELLI, Marcos Claudio. A Política Nacional de Saúde Integral de Lésbicas, Gays, Bissexuais e Transgêneros (LGBT) e o acesso ao Processo Transexualizador no Sistema Único de Saúde (SUS): avanços e desafios. Ciência \& Saúde Coletiva. 22(5):1509-20, 2017.

PRADO, Elizabeth Alves de Jesus; SOUZA, Maria de Fátima. Políticas públicas e saúde da população LGBT: uma revisão integrativa. Tempus Actas de Saúde Coletiva. 11():69-80, 2017.

PREUSS, Lislei Teresinha; MARTINS, Dilermando Aparecido Borges. Reflexões acerca da política nacional de saúde integral LGBT nas regiões de fronteiras. Interações. 20(3):933-946, 2018.

QUERINO, Mirlene dos Santos; ALMEIDA, Sabrina; OLIVEIRA, Sara Carolina da Silva; UMANN, Juliane; FILHO, Iel Marciano de Moraes. Ações de enfermagem na implementação da Política Nacional de Saúde Integral de Lésbicas, Gays, Bissexuais, Travestis e Transexuais: revisão de literatura. Revista Científica Sena Aires. 6(1):46$58,2017$.

RIOS, Roger Raupp. Direitos Humanos LGBTIs e Sistema de Justiça: Standards de Proteção e Atuação do Poder Judiciário e do Ministério Público. Revista Direitos Humanos e Democracia. 8(16):138-51, 2020.

SANTOS, Juliana Spinula; SILVA, Rodrigo Nogueira; FERREIRA, Márcia de Assunção. Saúde da população LGBTI+ na Atenção Primária à Saúde e a inserção da Enfermagem. Escola Anna Nery. 23(4):1-6, 2019.

SANTOS, Lenir. Direito da saúdo no Brasil. Campinas, SP: Ed. Saberes. Edição: 1a 2010. 165p.

Vol. 03, N. 13, Jan. - Abr., 2021 - http://periodicoscientificos.ufmt.br/ojs/index.php/rebeh/index 
SARTI, Thiago Dias; OLIVEIRA, Denize Ornelas Pereira; CHUERI, Patrícia Sampaio; FONTENELLE, Leonardo Ferreira. Diversidade e direitos humanos na atenção primária à saúde. Revista Brasileira de Medicina de Família e Comunidade. 14(41):1-5, 2019.

SILVA, Amanda de Cassia Azevedo; ALCÂNTARA, Anelise Montañes; DE OLIVEIRA, Daniel Cavanese; SIGNORELLI, Marcos Claudio. Implementação da política nacional de saúde integral de lésbicas, gays, bissexuais, travestis e transexuais (PNSI LGBT) no Paraná, Brasil. Interface (Botucatu). 24:e190568, 2020.

TUSSI, Fernanda Pivato. Toda feita: o corpo e o gênero das travestis. Horizontes Antropológicos. 12(26):323-27, 2006.

\section{Reviewing the health of LGBT in the context of primary health care}

Abstract: This paper constitutes a critical reflection on the National Policy on Integral 326 Health of Lesbians, Gays, Bisexuals, Transvestites and Transsexuals (NPIHLGBT), with a special focus on the context of Primary Health Care (PHC). This is a mixed qualitative study, of documentary and literature review, which addresses the issue of assistance to the social and health needs of users with multiple gender identities and sexual orientations within the Unified Health System (UHS). The work aimed, concomitantly, at highlighting historical aspects that concern the formulation, implementation and deployment of the NPIHLGBT in the UHS health care networks. Considering the objective outlined, scientific articles with such investigative direction were included. The articles should have been developed in the PHC setting and written in Portuguese. In the selection of materials, we chose to use the following descriptors: LGBT Health; NPIHLGBT; PCH and UHS. Since it is one of the most recent specific national health policies of the UHS, the study showed a scarcity of studies focused on understanding the care and assistance available to the LGBT community in Brazil, informing that, although the implementation of the NPIHLGBT is considered one of the most important achievements in terms of social justice, future studies are still necessary, given that it is recognized the magnitude of the theme for the vindication of fundamental rights, especially because of the doctrinal principles that govern the PHC in the UHS: universality, integrality and equity. Thus, despite existing, resisting and occupying the spaces of Brazilian society, the effectiveness of the NPIHLGBT is still far from the desired goal.

Keywords: LGBT Health; Comprehensive LGBT Health Policy; Unified Health System; Health Equity.

Recebido: 21/03/2021

Aceito em: 20/04/2021 